\title{
Micro-Impact of the Pandemic by Covid-19 in the General Medicine: Clinical and Epidemiological Reflections from the Situation in Spain March 2020
}

\section{Turabian JL*}

Specialist in Family and Community Medicine, Regional Health Service of Castilla la Mancha (SESCAM), Spain

*Corresponding author: Jose Luis Turabian, Health Center Santa Maria de Benquerencia. Regional Health Service of Castilla la Mancha (SESCAM), Toledo, Spain, Email: jturabianf@ hotmail.com

\section{Research Article}

Volume 4 Issue 2

Received Date: March 24, 2020

Published Date: April 09, 2020

DOI: $10.23880 /$ eij-16000141

\section{Abstract}

The COVID-19 epidemic, in just a few weeks, is challenging the current Primary Care model, centered on a demand that the general practitiones (GPs) believed was ungovernable; It is forcing to implement new interventions and to reflect sharply on the role of the GP to achieve the maximum resolution of existing health needs in the most effective, efficient, equitable and accessible way, and, on the other hand, to seek the sustainability of the system. These sudden changes affect GP's crucial roles as gatekeeper, family and community doctor, and epidemiologist, to avoid overloading tertiary hospitals and other acute care facilities. This article reflects, from the author's experience in Toledo (Spain) to March 18, 2020, on the questions related to COVID-19: What are implications on psychosocial determinants in my area of work? What implications will it have in my community? What effects will quarantine have on my patients? How many patients will I have? Who will be the most vulnerable patients? What implications will it have on primary care health personnel? What implications will it have on the organization of primary care? What implications regarding home treatment of patients and contacts? What implications in my patients' treatments? What implications will it produce in teaching at my health center? What implications for my health and that of my family?

Keywords: Coronavirus; COVID-19; SARS-CoV-2; General Practice; Epidemiology; Infectious Disease; Outbreak Modelling

Abbreviations: COVID-19: Current Outbreak of Coronavirus Disease 2019; SARS-Cov-2: Severe Acute Respiratory Syndrome Coronavirus 2; GPs: General Practitioners; CFR: Case Fatality Rate; WHO: World Health Organization; PCR: Polymerase Chain Reaction; ACE: Angiotensin-Converting-Enzyme; ARBs: AngiotensinReceptor Blockers; NSAIDs: Non-Steroidal Anti-Inflammatory Drugs.

\section{Introduction}

The current outbreak of coronavirus disease 2019 (COVID-19), caused by the severe acute respiratory syndrome coronavirus 2 (SARS-CoV-2) [1], continues to spread, affecting 176 countries and territories around the world, with their figures are rapidly changing, and being a public health emergency of international concern [2,3]. From December 31, 2019 to March 19, 2020, 213254 cases of COVID-19 have been reported (according to the applied case definitions and testing strategies in affected countries), including 8,843 deaths. International data from the European Center for Disease Prevention and Control indicate a similar pattern in coronavirus cases reported in different countries during the first 10 days after the case count exceeds 500 [4].

The news from China, Iran, Italy, Spain, and other areas 


\section{Epidemiology International Journal}

hard hit by Coronavirus are chilling. Currently, it is recognized that transmission in new cases is already largely communitybased. As of March 18, 2020, there are 74,399 confirmed cases in Europe, and 13,716 confirmed cases in Spain, and this information is under continuous review [5]. As the COVID-19 pandemic evolves, we gradually are accumulating knowledge to guide patient care. Although most disease is mild ( $80-85 \%), 12-15 \%$ have a serious illness, and between $1-5 \%$ a potentially fatal disease, which can require intensive care for issues such as acute respiratory distress syndrome, shock, and multi organ failure [6,7]. Results from various specialist groups around the world are beginning to converge on the true case fatality rate of COVID-19, which appears to be around 1 percent $[8,9]$. As of the writing of this article, March 18, 2020, there are 5,717 hospitalized patients in Spain, of whom 774 remain in the intensive care units.

Recognizing that lack of preparation for an outbreak is a major global health challenge, sharing knowledge on how to care for the minority of patients who become critically ill is important. In Italy, previously "normal" hospitals have been transformed into giant intensive care units. But it is also very important how to deal with infection in primary care and in the community, which means attending to most cases [10]. Spain, with more than 11,000 positives and 500 deaths (as of March 18, 2020), has become the second country in the world that registers more new cases every day. Flattening the curve - slowing down the spread of COVID-19 across space and time - and therefore preventing many people from becoming infected at the same time is a critical goal in not saturating the healthcare system. The virus is in Spain in exponential growth phase and shows a similar rate to that of Italy. There is also an exponential increase in the different Spanish autonomous communities. The health care system cannot support a massive influx of infectious cases to emergency departments and hospitals. In this way, patients with mild symptoms should stay home and in their community when possible. This huge task falls on the general practitioners (GPs), other health and non-health personnel from Primary Care, and the local community itself.
For most illnesses the GP is the first point of contact in the health care system and he looks after a population whose age and sex composition is known. The essence of general medicine is to assist individuals in families and communities, and this implies, on the one hand a good continuity of care, and moreover a knowledge of the nature of diseases in the community [11]. The GP is in a rare position that combines the individual and community dimensions, and there is a great need to extend the clinical horizons to the epidemiological and community aspects of care. The "path of all patients" begins and ends with the GP $[12,13]$. All these characteristics of the GP can also be applied and are affected by the current outbreak of COVID-19.

In this tragic scenario, this article, which is a personal view, aims to conceptualize and summarize the micro-impact of the pandemic by COVID-19 in the consultations of general medicine based on an unsystematic or opportunistic search for information and the author's experience.

\section{Methods}

The comments in this article should be considered as a personal point of view, based on the author's experience during 30 years of work in general medicine, plus an unsystematic or opportunistic search for information. The search for information was based on a non-systematic review considering the bibliographic references of selected articles, reviews of books related to the topic and opportunistic searches on the Internet. This non-systematic review was carried out, which aimed to explore, describe and discuss the topic of the micro-impact of the pandemic by COVID-19 in the consultations of general medicine, in a broad way.

\section{Discussion}

Presents some of the micro-impact of the pandemic by COVID-19 in the consultations of general medicine, which will be discussed below (Table 1).

\section{MICRO-IMPACTS OF THE PANDEMIC BY COVID-19 IN THE CONSULTATIONS OF GENERAL MEDICINE}

1 -What implications and what consequences will psychosocial determinants produce in relation to COVID-19 in my area of work?

2 -What implications will COVID-19 produce in my community?

3 -What effects will quarantine by COVID-19 produce in my patients?

4 -How many patients with COVID-19 will I have on my list of people that I see in my office?

5 -Who will be the most vulnerable patients to present complications if they fall ill with COVID-19 among those on my patient list or community?

6 -What implications will COVID-19 have on primary care health personnel?

7 -What implications will COVID-19 have on the organization of primary care? 


\section{Epidemiology International Journal}

\begin{tabular}{|c|l|}
\hline 8 & $\begin{array}{l}\text {-What implications will COVID-19 produce regarding treatment of patients and contacts and in the treatments of my } \\
\text { habitual patients? }\end{array}$ \\
\hline 9 & -What implications will COVID-19 produce in teaching at my health center? \\
\hline 10 & -What implications will COVID-19 have on my health and that of my family? \\
\hline
\end{tabular}

Table 1: Micro-Impacts of the Pandemic by Covid-19 in the Consultations of General Medicine.

\section{What Implications and What Consequences will Psychosocial Determinants Produce in Relation to COVID-19 in my Area of Work?}

The GP should keep in mind the effect and consequences of the social determinants of health among the patients with the COVID-19 he or she serves (different social groups, genders, sexualities, and races). This situation may be an opportunity to reflect on the ways in which the social determinants of health are left out during a crisis scenario, why this happens. It is true that the COVID-19 pandemic is a situation that is not yet well understood; a new virus, without prior immunity in the community, with powerful social determinants such as large urban populations, great mobility of people around the world, underestimation of dangers, etc. The most visible reasons for the severity of the infection, regardless of genetics, virus typologies, etc., are the population structure. Europe is an old society and Korea, Africa, and a good part of Southeast Asia, is young, therefore Europeans are much older and more susceptible to gravity and death [14].

On the other hand, although COVID-18 seems to be more frequent in men, the results for women in crisis situations are significantly worse. But, rarely are steps taken to address the social determinants of health, and political considerations always prevail, even during a humanitarian crisis. In particular, the structural drivers of outbreaks, such as gender inequalities and other social determinants of health, are often neglected in favor of addressing immediate biological threats with technical solutions. Different social groups, different genders, sexualities and races, have a different affectation, experience infectious outbreaks and give rise to responses to diseases in different ways. For example, the effects on maternal and child health, social and cultural characteristics which should be taken into account when developing information materials or intervention techniques, as well as initiatives that help combat infectious diseases through equity-based approaches. Usually, however, when we want to act quickly on an issue, we often think that consideration based on gender, social class, or ethical principles are less important than technical aspects, resulting in poor planning or intervention, limiting effectiveness [10].

Because deaths have been concentrated at older ages, tis fact highlight the important role of demography, particularly how the age structure of a population may help explain differences in fatality rates across communities and countries, and how transmission unfolds [15]. In addition, there may be different cultural factors in the community that affect transmission. Data from China say that between $75 \%$ and $80 \%$ of COVID-19 infections have occurred in family nuclei $[16,17]$. But the daily contact between young and old is not the same in all societies. It has been suggested that people between 30 and 49 years old who live with their parents exceed $20 \%$ in Italy, China or Japan, while in Germany they are just over 10\%, which would make important differences in the extent of outbreaks and mortality in different communities [18]. In addition, it must be borne in mind that the ecosystem has changed: the post-traumatic, social, economic and personal consequences of this crisis will last for a long time, and may serve to change the GP's and primary care's social vision, and how he/she applys it to your patients [19].

\section{What Implications Will COVID-19 Have in my Community?}

The guidelines of not carrying out the diagnostic test for SARS-CoV-2 in people with a clinical picture of mild acute respiratory infection in the community, as happens on this date of March 18, 2020 in Spain, in turn cause a "epidemic of anxiety "in the community:

- In patients called "possible cases" (which are actually "all" cases with mild acute respiratory infection, since there is no diagnostic test)

- In your caregivers, relatives and other previous work, school, neighborhood contacts, etc.

People with mental health conditions could be more substantially influenced by the emotional responses elicited by the COVID-19 epidemic, resulting in relapses or worsening of an existing mental health condition due to the high susceptibility to stress in comparison with the general population. Furthermore, people with mental disorders may be exposed to more barriers to accessing timely health services, due to discrimination associated with mental illness in healthcare settings, cognitive decline, and little awareness of risk [20]. Social isolation among older adults is a serious public health problem due to their increased risk of cardiovascular, autoimmune, neurocognitive, and mental health problems. Social disconnection puts older adults at higher risk for depression and anxiety [21]. 


\section{Epidemiology International Journal}

On the other hand, this situation originates an "epidemic of sick leave", be it in the possible cases, the "possible" contacts and in the asymptomatic people but distressed to be in situation of some type of work or family risk, or simply out of anxiety. Clear, evidence-based communication is critical to manage public fear. Uncontradictory messaging based on the best science will improve compliance and effectiveness of voluntary self-isolation, and other voluntary social distancing measures [22].

All people are very nervous about the coronavirus. Thus, there may be acts of violence and stigmatization by accusing people from outside the community of having introduced the coronavirus in the neighborhood or town. Neighbors can turn a resident "into a plague" and stigmatize his entire family, raising social alarm throughout the local community. In the context of COVID-19, certain groups, such as Chinese and other Asian, Italian, or people from the areas with the highest incidence within the same country or city, are stigmatized. According to this reaction, communities have already begun to face attacks on individuals, linked to fears about the virus [22]. On the other hand, children are less affected, but they are very likely a major source of the virus. And in another sense, people residing in close living quarters are especially vulnerable to COVID-19 and will need special attention both to minimize transmission risk and address their healthcare needs in the context of an outbreak. These populations include those living in nursing homes or other congregate facilities, as well as, the homeless living on the streets or in homeless shelters [23].

Another community effect that the GP has to take into account is the mandatory quarantine in countries or cities, or the quarantine of patients and contacts. As COVID-19 spreads across the world, governments have imposed robust measures of social alienation and quarantines and travel bans on an unprecedented scale. Although, it must be recognized that travel bans and mandatory quarantines alone cannot end the outbreak. It is very tempting to attribute causality where there may be nothing but simple association: in both China and South Korea the reduction of cases is attributed to the measures implemented and in both cases what we see is perhaps only the evolution of a normal epidemic outbreak (in the usual sense) with a normal epidemic curve (in the statistical sense). In Spain, since March 15, 2020, there is a declaration of "state of alarm" that forces the isolation of all inhabitants with very few exceptions. Multiple aspects of quarantine can increase psychological distress in both the general public and healthcare workers, particularly a mix of anxious and depressive symptoms, which can distort your thinking and lead to maladaptive behaviors such as excessive avoidance and stigmatization. Critically important health workers can be particularly vulnerable. But strategies can minimize these stressors: Providing detailed information about the virus, the risk of contagion, lethality, and justification for quarantine, along with adequate supplies and facilitating virtual social connections, are the only antidotes that can calm anxieties of people [24].

\section{How Many Patients with COVID-19 will i have on my List of People That I See at my Office as GP?}

The GP should have a certain "situational awareness" regarding the general population and its community and list of patients, including the rate of hidden or undiagnosed cases. The failure to perform the diagnostic test on patients with mild respiratory symptoms in the community in Spain (since the instructions are, as of March 18, 2020, that diagnostic test for SARS-CoV-2 be performed at people with a clinical picture of acute respiratory infection admitted to the hospital, or respiratory infection of any degree in health personnel. Similarly, routine diagnostic tests are not performed on contacts), carries to an "epidemic of clinical and epidemiological ignorance." In Spain, with a scenario on March 18, 2020, of widespread sustained transmission, and with more than 13,716 positives and 558 deaths, making it the second country in the world that registers more new cases every day, according to the health authorities, and flattening the curve and, therefore, preventing many people from becoming infected at the same time is the main objective so as not to saturate the health system; the virus is in Spain in exponential growth phase and shows to this date, a rate similar to that of Italy. Also this increase is in the different Spanish autonomous communities, although have an uneven distribution, including that of Castilla-La Mancha with 662 confirmed cases of coronavirus and 23 dead; And with its capital, Toledo, where the author works, with 179 cases; 7 deceased [25].

Since the tests are not available to everyone, the numbers do not accurately reflect the extent of transmission in communities around the world. For Spain, the official incidence figures $(11,000$ positive as of March 18, 2020) are therefore false; perhaps, one could speak of "minimal incidence." In fact, the only most reliable epidemiological figure is mortality or case fatality. The case fatality rate (CFR) of COVID-19 is the number of confirmed deaths due to COVID-19 divided by the total number of confirmed cases of infections with the coronavirus SARS-CoV-2. CFR should not be confused with the mortality rate or death rate which is simply the total number of deaths that occur during a specific time frame divided by the number of the total population at approximately the same time. Currently, we are more interested in the CFR because we see the number of cases growing and we want to know how many of these diagnosed cases will result in the death of the patients [14]

Consequently, the researchers attempt to calculate 
individual shoot size based on incomplete data. In this way, experts compare various lines of evidence. With official figures in hand, hospitalized patients account for almost half of all positives. This is another sign of under diagnosis. The World Health Organization (WHO) estimates are that about $20 \%$ of COVID-19 patients require hospital admission. Data from China suggests that about three weeks elapse between the time a person feels sick and dies from COVID-19. And if you assume a CFR of about 1\%, a calculation at the end suggests that each death represents about 100 cases in the first week. At this time, the epidemic can be expected to double every week if those cases are not identified and isolated, bringing the estimate to 400 at the time of death. Other experts have stated that we must multiply by 27 , at least, from those detected, to approximate the actual number of infected [9,26-29].

Thus, with respect to Spain, 558 deaths (as of March 18, 2020), it is possible to hypothesize about the true average number of infected in the community $(558 \times 800=446,400$; or, 13,716 positives $\times 27=370,332$, vs. the 13,716 official positives!) (Figure 1). Applying these estimates to a region (for example, in the Spanish region where the author works, Castilla-La Mancha, with 567 official cases and 17 deaths X $800=13,600$ real cases (Figure 2). That is, 13,600 real cases minus 567 officially reported cases $=13,000$ undiagnosed, hidden cases, and with respect to a list of patients in a GP who cares for 2000 patients> 14 years of age (in Spain GPs care for people $>=14$ years of age), if there are 567 confirmed cases in a population of 2,035,505 inhabitants (population of Castilla-La Mancha) $>0$ years, for a list of patients in 2000, the GP will have approximately 1 "official" case. Indeed, the author of the article, as of this date, has 1 case declared and admitted to the hospital. However, if there are 15,000 real cases compared to the 567 confirmed cases in Castilla-La Mancha, for 1 declared in my list, there will be 26 hidden real cases! (Figure 3). This implies the need for strong measures of social distancing.

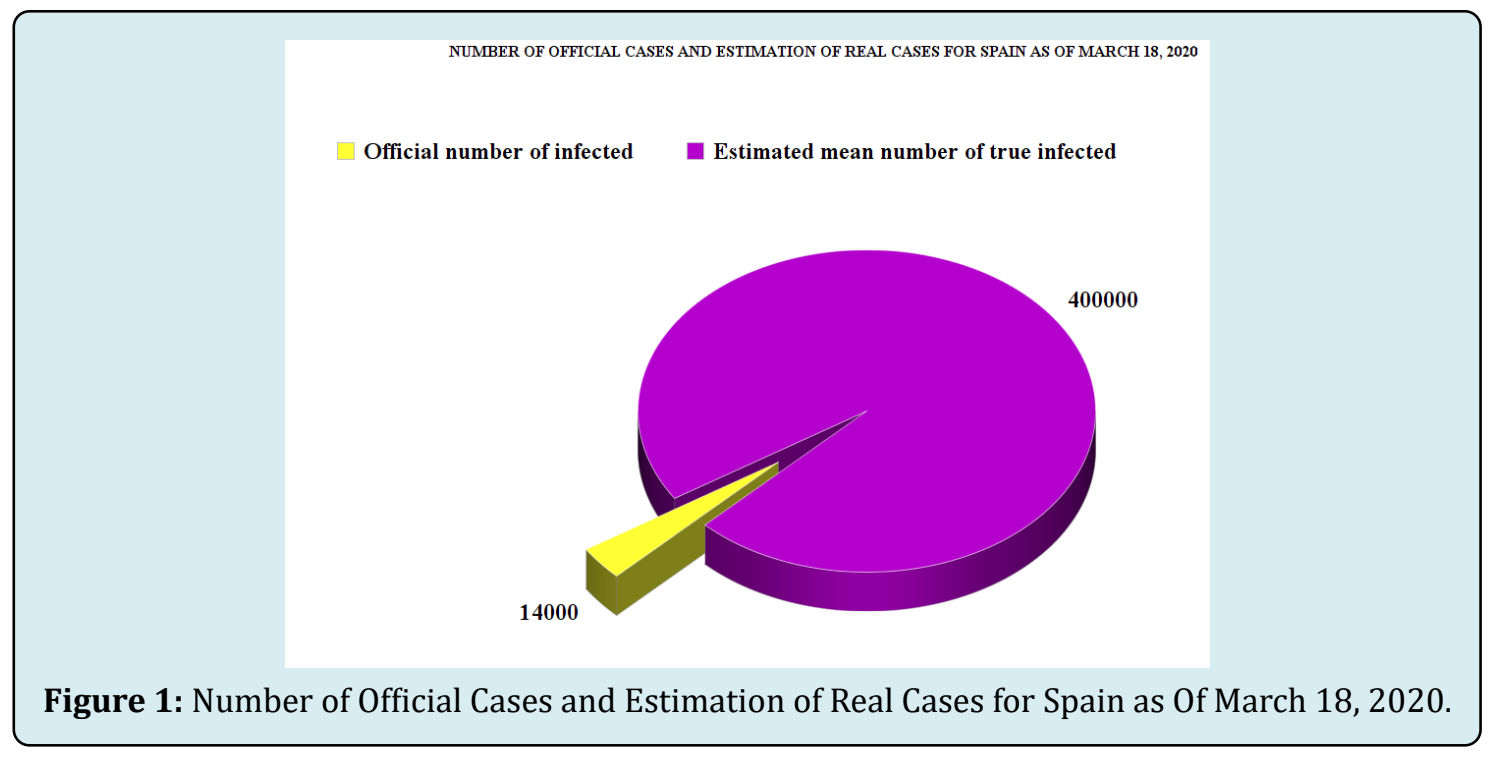

NINBBER OF OFFTCIAL CASES AND ESTIMATTON OF REAL CASES FOR THE CASTILLA-LA MANCHA REGION (SPATV) AS OF MARCH 18, 2020

Official number of infected Estimated mean number of the true infected

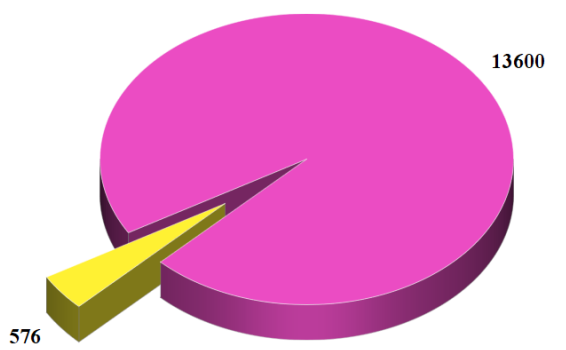

Figure 2: Number of Official Cases and Estimation of Real Cases for the Castilla-La Mancha Region (Spain) As of March 18, 2020. 
NUMBER OF OFFICIAL CASES AND ESTIMATION OF REAL CASES FOR A GP IN CASTILLA-LA MANCHA (SPAIN) AS OF MARCH 18, 2020

Official number of infected $\quad$ Estimated mean number of true infected

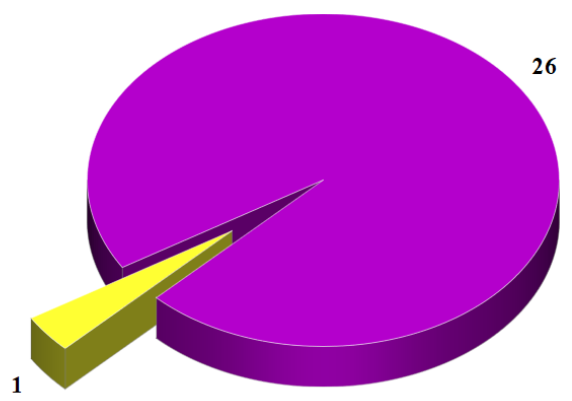

Figure 3: Number of Official Cases and Estimation of Real Cases for a General Practitioner in the Castilla-La Mancha Region (Spain) As of March 18, 2020.

Hence, assuming that the number of asymptomatic patients or those with few symptoms is several times the number of those with overt symptoms, mortality would be much lower than $1 \%$. Hence, according to some experts, COVID-19 at a general level (mild and severe cases) would behave like a severe seasonal flu, given that in this the death rate is $0.1 \%$, or like a pandemic flu like those that happened in 1957 and 1968, but very different from SARS or MERS in which the death rates were from 10 to $36 \%$. This has to make us think that other epidemics will come and that they will probably be much more lethal and we should learn from the current one [30-32].

WHO is urging governments to conduct more tests for COVID-19 due to concerns about underreporting of cases in many countries around the world. As more and more nations have introduced stringent measures to try to delay the spread of the virus, the WHO cautions that evaluating the impact of these measures will only be possible with accurate data on the disease. It also warns that the lack of data on how many people have the disease could undermine containment and mitigation efforts in many countries [33]. On the other hand, in some countries, such as Spain, today, data on basic epidemiological variables such as age and sex related to CFR, hospital admissions, ICU admissions, number of tests carried out, etc. are not yet known [34].

\section{Who will be the Most Vulnerable Patients to Present Complications if they Fall Ill with COVID-19 among Those on My Patient List or Community?}

There are certain patients or risk groups that are more likely to develop severe COVID-19 disease [35-38], and therefore should be more protected against the coronavirus, so it is important that they contact their GP, or that the GP identifies them in the records of his practice and contact them, so that they follow his recommendations for the prevention and control of his disease. For example, evidence suggests that diabetes may increase risk for infection from COVID-19 by 2- to 3-fold, independent of other medical problems such as cardiovascular disease. These groups are, at least, as of the date of writing this article:

a) People who are over 60 years old

b) Cardiovascular diseases and high blood pressure

c) Diabetes

d) Chronic lung diseases

e) Cancer

f) Immunosuppression

g) Pregnancy

h) People with HIV

About four in ten adults ages 18 and older have a higher risk of developing serious illness if they are infected with coronavirus, due to their older age (60 and older) or health condition. Most of those at higher risk of developing a serious illness are older. Adults who are both older and have these underlying medical conditions have an even greater risk of developing severe illness if they become infected [39].

\section{What implications will COVID-19 have on primary care health personnel?}

Health workers have a physical and mental exhaustion, the torment of difficult triage decisions, and the pain of losing patients and colleagues, all in addition to the infection risk [40]. Hospitals and health centers can become vectors 


\section{Epidemiology International Journal}

of infection from patient to patient within the center itself and transmit the infection to the community, in addition to affecting to the health personnel itself. Airborne or aerosol transmission, more than two meters, is believed to occur during invasive medical procedures of the respiratory tract. During the outbreak of severe acute respiratory syndrome (SARS) in 2003, the presence of the virus in the air of the rooms of hospitalized patients was already confirmed [41]. In Spain, of the total number of infected as of March 18, 2020, 13,716 positive 455 are healthcare personnel, "an undesirable number" [42]. At the Health Center where the author works, with 23 nurses and GPs, in Toledo, Spain, at the date of writing, there is a nurse with COVID-19.

On the other hand, health personnel go crazy going from guide to guide, from instruction to instruction. Coronavirus upends the routine; it exposes the farce of administrative bloat. There is almost no time to know if you are up to date. Coronavirus sufferers began arriving at hospitals and GPs offices little by little, but in a couple of days they multiplied in incalculable quantities. The crisis unleashed by the coronavirus has been especially difficult for health workers to manage because it has confronted them with their worst enemy: uncertainty. What happens in the hospital, at another level also happens in general medicine: for a GP it is very uncomfortable to find that patients with a respiratory infection, that they do not know how to catalog or treat, do not stop arriving. The coronavirus forces a change in the rules. Sending an elderly patient to a hospital for an urgent evaluation of benign arrhythmias was fine; now it is not. Finally, the coronavirus may emphasize what medicine is for, that is, treating the sick, not the healthy [43]. In addition, the guidelines of not performing the diagnostic test for SARS-CoV-2 in people with a clinical picture of mild acute respiratory infection in the community, increases distress in all primary care personnel who do not know the disease and the patient's risk who is attending.

Regarding the use of protective measures, one must face the lack of masks and the controversy of their protective effect. Ten hours with the same mask? Are surgical masks effective in preventing coronavirus infection among people? According to the recommendations on the use of masks, those known as surgical masks (the usual ones that we all use) only protect from the inside out, so they are the ones that patients should wear and, in theory, they should be changed every two hours of use to preserve filtering efficiency. Respiratory protection masks are those that should be worn by professionals who treat patients with respiratory infections and at a minimum should have a factor FFP2 (filtering protection up to 92\%), FFP3 being recommended (up to $98 \%$ in those techniques that generate aerosols (intubation, bronchoscopy, bronchoalveolar lavage, aspiration of bronchial secretions, etc.) However, I am not aware that surgeons change them every two hours, which means perhaps that either there is ignorance about it, or protection is more prolonged. No differences were found, in the flu rates of health personnel in contact with flu patients, if a surgical mask was used or the called N95 [44].

Regarding personal protective equipment (glasses, gloves, mask with filter and waterproof gown), of which at the date of this article there is only one in the health center where the author works, they are reserved for tasks at risk of splashing fluids. For those who work in hospitalization areas or in general medicine consultations with patients with COVID-19, it is enough that they wear the surgical mask throughout the day. The mask can be used while it is intact and dry [45]. In short, the coronavirus may teach us all the right ways to wear personal protective equipment. Keep in mind that COVID-19 virus isn't 'airborne' in the sense that it lingers infectiously in the air for some time, like measles. But the extent to which the coronavirus can be spread through the air, in the form of droplets from a sneeze or cough, is not yet known - and there is some disagreement among scientists about the very definition of airborne. The SARS-CoV-2 virus, can remain viable in aerosols for hours and on surfaces for days $[46,47]$.

\section{What implications will COVID-19 have on the organization of primary care?}

The characteristics of consultations in the health center are already changing and will do so even more: the majority are patients with respiratory problems; the others are canceling or not showing up for appointments or are very fast queries; scheduled patient visits are canceled, and more and more consultations are and will be by phone, without the physical presence of the patient. This logical trend towards telehealth services is also occurring elsewhere [48,49]. Thus if a patient has mild symptoms, they are asked to stay home; for moderate symptoms it might be sent to a separate area; if the patient is severe, he/she is not even visited, and is sent directly to the hospital.

The demand that seemed impossible to contain [50] at once has disappeared. The waiting rooms are almost empty. All non-urgent activity is suspended. But, this does not mean that all human and material resources are now destined to treat the pandemic: The world cannot be stopped. Other critical healthcare programs must be maintained during this crisis. People with chronic conditions depend on continuity of care to maintain their health [22]. It is clear that, in the midst of this crisis, there are people who break a leg, who have a heart attack, who need chemotherapy; an evaluation of each case is required.

The first step in the general medicine consultation is 


\section{Epidemiology International Journal}

a careful telephone triage. Clinicians are working out how to manage patients with COVID-19 or suspected of having COVID-19. When patients call to make an appointment with the GP, the call is passed to the consultation and the GP or a nurse speaks to find out how sick they are:

a) High fever?

b) Shortness of breath?

c) Do they have a chronic illness, such as diabetes, cardiovascular disease, or a lung condition, that increases risk for infection and complications?

If a patient has mild symptoms, they will be asked to stay home and the GP will contact them. For moderate symptoms, a conventional visit can be made, but the respiratory patient receives masks, separates, and is sent to a separate area. If the patient is severe, the GP send him directly to the hospital to the emergency room. These categories parallel the World Health Organization's designations of uncomplicated illness, mild pneumonia, severe pneumonia, acute respiratory distress syndrome, sepsis, and septic shock. In the current community-transmitted situation, people are no longer systematically asked about a history of travel to countries with high transmission. In theory, any patient with fever, cough, and shortness of breath should be evaluated immediately for COVID-19, using COVID-19 polymerase chain reaction (PCR). Although some author points out that it would start with a respiratory virus PCR panel to rule out other pathogens (if flu is negative and other common respiratory infections are negative, then they do a COVID-19 test), in the current pandemic situation, this does not seem to be a logical strategy. All patients with respiratory symptoms are treated as persons under investigation, for whom isolation precautions are required. In addition, for these patients, use of personal protective equipment by caregivers is required [51].

Although the World Health Organization (WHO) urged countries to test all mild cases, since it is the only way to measure the epidemic, control cases and isolate them so that they do not continue to spread the disease (the spread of the coronavirus in Wuhan was mainly due to the undetected cases; and it is something that has probably happened in Italy and very possibly also in Spain), at the date of writing this article, in Spain they are not being carried out, with the consequent lack of reliability regarding the epidemic provided by official data [52].

Thus, it is essential that PCR is available to GPs. The GPs are the most experienced in dealing with the bulk of respiratory infections on a daily basis, and that they do it in the most complete uncertainty with very good results. This is based on the knowledge provided by continued care and context [53-55]. This knowledge is very important in the beginnings and early stages of any clinical process, including Covid19 [56].

\section{What Implications will COVID-19 Produce Regarding Treatment for Patients and Contacts?}

Certain medications increase the number of so-called ACE2 receptors on cell surfaces. SARS-CoV and SARS-CoV-2 use the same keyhole to enter cells, the ACE2 receptor. There is an abundance of this receptor in the cells of the lower part of the lung, which may explain the high incidence of pneumonia and bronchitis in people with severe COVID-19 infection. This is because the ACE2 enzyme is an important regulator of the immune response, especially inflammation [57]. And, this is consistent with the epidemiological risk for severe disease seen in patients with cardiovascular disease and hypertension in China. Researchers proposed that angiotensin-converting-enzyme (ACE) inhibitors or angiotensin-receptor blockers (ARBs) could increase the risk for developing severe COVID-19. The coronavirus binds to target cells through ACE 2, the expression of which is increased when patients take these drugs [58]. However, there is no clinical data to support that this is actually true, and so, patients with COVID-19 who have underlying hypertension, heart failure, or ischemic heart disease should not stop taking their ACE inhibitors or ARBs, according to a new statement from the American Heart Association, the American College of Cardiology, and the Heart Failure Society of America, the European Society on Hypertension, and the Council on Hypertension of the European Society of Cardiology $[59,60]$. In this sense, reducing the abundance of ACE2 receptors in older adults may leave them less able to cope with SARS-CoV-2, although this hypothesis, as well as the influence of ACE inhibitors or ARBs, still needs more research.

On the other hand, another concern relates to non-steroidal anti-inflammatory drugs (NSAIDs) and acetaminophen (paracetamol). When these drugs reduce fever, patients may feel more comfortable, but their lower temperatures may short-circuit the body's main defense against infection. Studies have found that if people infected with a variety of viruses and other microorganisms reduce fever, with NSAIDS, or with acetaminophen, their symptoms may last longer and continue to clear the virus longer, meaning they can be contagious for periods longer. The immune system works best when the body temperature is higher, allowing it to more efficiently kill viruses and bacteria. Dozens of studies, in animals, reptiles, and humans, have found that fever is beneficial in fighting infection. There is at least a theoretical danger that fever reducers, including acetaminophen, may have a similar effect in patients with the coronavirus. Prolonged illness or the complications of respiratory infections may be more common when NSAIDs 


\section{Epidemiology International Journal}

are used - both respiratory or septic complications and cardiovascular complications. Iuprofen's anti-inflammatory properties could "dampen down" the immune system, which could slow the recovery process. It was likely, based on similarities between the new virus (SARS-CoV-2) and SARS I, that covid-19 reduces a key enzyme that part regulates the water and salt concentration in the blood and could contribute to the pneumonia seen in extreme cases. Ibuprofen aggravates this, while paracetamol does not [61]. Although no research has yet been done, it may be reasonable for a person infected with the coronavirus to avoid both types of pain relievers [62].

Antibiotics are reserved for patients suspected of having concomitant bacterial or fungal infections. Immunosuppressed patients are at high risk of secondary infection [51]. Pediatric cases of COVID-19 infection are typically mild, but underlying coinfection may be more common in children than in adults. This finding may suggest that routine antibacterial treatment should be considered in pediatric patients. In children, their young immune systems, ACE2 receptor levels, and even exposure to other coronaviruses might play a role in their resilience $[63,64]$.

Lastly, home treatment of cases and contact isolation entails, as part of the GP indications, standards for everyday prevention actions (such as clean and disinfect frequently touched surfaces and objects, for example: tables, countertops, light switches, doorknobs, and cabinet handles, etc.) [65].

\section{What Implications will COVID-19 Produce in Teaching at My Health Center?}

The cancellation of rotations of residents of the hospital, or of residents of general medicine who are on duty also the hospital, must occur. The health center and hospital are vectors of contagion, and the healthcare professional can carry the infection from one place to another. If this doctor is affected, it will mean a significant deficit in healthcare work. $41 \%$ of COVID-19 cases in Wuhan resulted from a hospitalrelated transmission. Health care providers are at increased risk of developing the disease and spreading it. Occupational stress is believed to weaken their immune systems, and close and intimate patient care can lead to exposure to an increased viral load [66].

\section{What implications will COVID-19 have on my health and that of my family?}

Health workers may have to face social stigma during this outbreak, and on the other hand, they put their families at risk at home. Are we being irresponsible with our families hugging them or kissing them good night? [66].

\section{Conclusion}

Clearly, it is difficult to learn beforehand how to deal with the unpredictable and ever-changing environment of biological, socioeconomic, and political factors that determine an outbreak. Actors have little time to consider the multiple consequences of decisions and hesitate to implement risky innovations during crises. The COVID-19 epidemic, in just a few weeks, is challenging the current Primary Care model, centered on a demand that the GPs believed was ungovernable; It is forcing to implement new interventions and to reflect sharply on the role of the GP to achieve the maximum resolution of existing health needs in the most effective, efficient, equitable and accessible way, and, on the other hand, to seek the sustainability of the system. These sudden changes affect GP's crucial role as guardian to avoid the overload of hospitals, the organization of general medicine consultations, relationships with our patients, the concepts of risk groups, the involvement of the community, the treatments that seemed immovable, coordination with hospital, the teaching, the opinions about officials, managers, politicians and experts, the financing of primary care centers, and our own personal and family experiences.

\section{References}

1. Wei X, Li X, Cui J (2020) Evolutionary Perspectives on Novel Coronaviruses Identified in Pneumonia Cases in China. National Science Review 7(2): 239-242.

2. Editorial (2020) COVID-19, a pandemic or not? Lancet Infect Dis 20(4): 383.

3. Covid-19 Coronavirus Outbreak.

4. European Centre for Disease Prevention and Control (2020) An agency of the European Union. Situation update worldwide.

5. Ministerio de Sanidad y Consumo, España.

6. Wu Z, McGoogan JM (2020) Characteristics of and important lessons from the coronavirus dsease 2019 (COVID-19) outbreak in China: summary of a report of 72314 cases from the Chinese Center for Disease Control and Prevention. JAMA: 1-4.

7. Baud D, Qi X, Nielsen-Saines K, Musso D, Pomar L, et al. (2020) Real estimates of mortality following COVID-19 infection. Lancet Infect Dis pp: 1.

8. Murthy S, Gomersall CD, Fowler RA (2020) Care for critically ill patients with COVID-19. JAMA pp: 3633.

9. Adam D (2020) Modelers Struggle to Predict the Future of the COVID-19 Pandemic. Disease experts have largely 
focused on how we got to where we are now with coronavirus infections. Improved data collection and sharing can enhance projections of what's to come. The Scientist.

10. Smith J, Sears N, Taylor B, Johnson M (2020) Serious games for serious crises: reflections from an infectious disease outbreak matrix game. Globalization and Health 16(18): 1-8.

11. Turabian JL (2017) The Variation of Seasonal Diseases in Family Medicine Depends on Infectious Diseases and these are Mainly Respiratory Diseases. J Gen Pract 5(3): $1-6$.

12. Turabian JL (2017) Prevalence of Chronic Diseases: in Defence of Epidemiological Craftsmanship in Family Medicine. CP Epidemiology 1(1): 1-13.

13. Turabian JL (1995) Cuadernos de Medicina de Familia y Comunitaria. Una introducción a los principios de Medicina de Familia. [Notebooks of Family and Community Medicine. An introduction to the principles of Family Medicine]. Madrid: Díaz de Santos.

14. Backhaus A (2020) Coronavirus: Why it's so deadly in Italy. Demographics and why they are a warning to other countries.

15. Mills M (2020) Demographic Science COVID-19.

16. McNeil Jr DG (2020) Inside China's All-Out War on the Coronavirus. Dr. Bruce Aylward, of the W.H.O., got a rare glimpse into Beijing's campaign to stop the epidemic. Here's what he saw. The New York Times.

17. Report of the WHO-China Joint Mission on Coronavirus Disease 2019 (COVID-19). 16-24 February 2020.

18. Kuhn M (2020) Twitter.

19. Ruiz Téllez Á (2018) La sanidad eludida. [Bypassed healing]. Almería, España: Grupo Editorial Círculo Rojo SL Colección: Investigación.

20. Yao H, Chen JH, Xu YF (2020) Patients with mental health disorders in the COVID-19 epidemic. Lancet Psychiatry 7(4): 1.

21. Armitage R, Nellums LB (2020) COVID-19 and the consequences of isolating the elderly. Lancet Public Health.

22. Achieving a fair and effective Covid-19 response: an open letter to Vice-President Mike Pence, and other federal, state and local leaders from public health and legal experts in the United States (2020).

\section{Epidemiology International Journal}

23. Parmet WE, Sinha MS (2020) Covid-19 - The Law and Limits of Quarantine. N Engl J Med: 1-3.

24. Brooks SK, Webster RK, Smith LE, Woodland L, Wessely S, et al. (2020) The psychological impact of quarantine and how to reduce it: Rapid review of the evidence. Lancet 395(10227): 912-920.

25. Consejería de Sanidad. Castilla-La Mancha. Spain.

26. Maxmen A (2020) How much is coronavirus spreading under the radar? Three leading health officials talk about gauging the size of local outbreaks, and why containment strategies aren't futile yet. Nature.

27. McBryde E (2020) The value of early transmission dynamic studies in emerging infectious diseases. Lancet Infect Dis pp: 1-2.

28. Kucharski AJ, Russell TW, Diamond C, Liu Y, Edmunds J, et al. (2020) Early dynamics of transmission and control of COVID-19: a mathematical modelling study. Lancet Infect Dis pp: 1-7.

29. Pueyo T (2020) Coronavirus: [Why We Must Act Now. Politicians, businessmen, associations and communities: What should they do and when?].

30. Fauci AS, Lane HC, Redfield RR (2020) Covid-19 -Navigating the Uncharted. N Engl J Med 382(13): 12681269.

31. Zhou F, Yu T, Du R, Fan G, Liu Y, et al. (2020) Clinical course and risk factors for mortality of adult inpatients with COVID-19 in Wuhan, China: a retrospective cohort study. Lancet 395(10229): 1054-1062.

32. Lewis R (2020) Risk Factors for Death From COVID-19 Identified in Wuhan Patients. Medscape.

33. Offord C (2020) Governments Must Ramp Up COVID-19 Testing, Says WHO. The Scientist.

34. Simó J (2020) Health, money and primary care.

35. Enfermedad por coronavirus, COVID-19 Actualización; 17 de marzo 2020. Centro de Coordinación de Alertas y Emergencias Sanitarias. Ministerio de Sanidad. España. Informe Técnico.

36. CDC (2020) Are You at Higher Risk for Severe Illness? Coronavirus Disease 2019 (COVID-19).

37. Barclay L, Nyarko E (2020) Are Diabetes, CVD Associated With Worse COVID-19 Prognosis?. Medscape.

38. Liang W, Guan W, Chen R, Wang W, Li J, et al. (2020) Cancer patients in SARS-CoV-2 infection: a nationwide 
analysis in China. Lancet Oncol 21(3): 335-337.

39. Koma W, Neuman T, Claxton G, Rae M, Kates J, et al. (2020) How Many Adults Are at Risk of Serious Illness If Infected with Coronavirus?. Global Health Policy.

40. Editorial (2020) COVID-19: protecting health-care workers. Lancet 395(10228): 922.

41. Booth TF, Kournikakis B, Bastien N, Ho J, Kobasa D, et al. (2005) Detection of Airborne Severe Acute Respiratory Syndrome (SARS) Coronavirus and Environmental Contamination in SARS Outbreak Units. The Journal of Infectious Diseases 191(9): 1472-1477.

42. A $43 \%$ rise in one day brings deaths to more than 500 (2020) Underdiagnosis of infections, numbering more than 11,000, hides the extent of the epidemic and the actual case-fatality rate. El País.

43. Mandrola J (2020) Will the Coronavirus Pandemic Trim the Nonsense in U.S. Healthcare?. Medscape.

44. Radonovich LJ, Simberkoff MS, Bessesen MT (2019) N95 Respirators vs Medical Masks for Preventing Influenza Among Health Care Personnel: A Randomized Clinical Trial. JAMA 322(9): 824-833.

45. Macpherson M (2020) Inquietud en los hospitales por la falta de material y cambios de normas por el virus. La Vanguardia.

46. van Doremalen N, Bushmaker T, Morris DH (2020) Aerosol and Surface Stability of SARS-CoV-2 as Compared with SARS-CoV-1. N Engl J Med pp: 1-3.

47. They Say Coronavirus Isn't Airborne-but It's Definitely Borne By Air. WIRED on Covid-19 (2020) Wired.

48. Greenhalgh T, Wherton J, Shaw S, Morrison C (2020) Video consultations for covid-19. BMJ 368: 998.

49. Getting Paid. A blog from JFP Journal (2020) Coronavirus (COVID-19): new telehealth rules and procedure codes for testing.

50. Turabian JL (2019) Suggestions to Address the Increase in Demand and Costs in General Medicine: Escaping From a "Black Hole" and from Boomerang Effect. J Qual Healthcare Eco 2(3): 1-9.

51. Lewis R (2020) So You Have a COVID-19 Patient; How Do You Treat Them?. Medscape.

52. Linde $P$ (2020) No estamos en el máximo de la epidemia, sino al inicio. David Nabarro, encargado de la OMS para la Covid-19 en Europa, pinta un futuro lleno de

\section{Epidemiology International Journal}

incertidumbres. El País.

53. Turabian JL (2020) Epidemiological Value of Continuity of Care in General Medicine (Part one of Two). Epidemol Int J 4(1): 1-6.

54. Turabian JL (2017) For Decision-Making in Family Medicine Context is the Final Arbiter. J Gen Pract (Los Angel) 5(4): 1-2.

55. Turabian JL (2020) Epidemiological Value of Continuity of Care in General Medicine (Part Two). Epidemol Int J 4(1): 1-7.

56. Simó J (2020) Covid 19 Propagation and Bolt: Now What?. Salud, dinero y atención primaria.

57. Zou Z, Yan Y, Shu Y, Gao R, Sun Y, et al. (2014) Angiotensinconverting enzyme 2 protects from lethal avian influenza A H5N1 infections. Nat Commun 5(3594): 1-7.

58. Fang L, Karakiulakis G, Roth M (2020) Are patients with hypertension and diabetes mellitus at increased risk for COVID-19 infection?. Lancet Respir Med pp: 21.

59. Patients taking ACE-i and ARBs who contract COVID-19 should continue treatment, unless otherwise advised by their physician. Statement from the American Heart Association, the Heart Failure Society of America and the American College of Cardiology. Newsroom.

60. Cequier A, Cosín J, Arrarte V, García Pinilla JM (2020) There is no clinical or scientific evidence to discontinue ACEI and ARA treatments due to COVID-19 infection [Article in Spanish]. Sociedad Española de Cardiología.

61. Day M (2020) Covid-19: ibuprofen should not be used for managing symptoms, say doctors and scientists. BMJ 368: 1086.

62. Kolata G (2020) Is Ibuprofen Really Risky for Coronavirus Patients? The New York Times.

63. Worcester S (2020) COVID-19 Characteristics Differ in Children vs Adults. Medscape.

64. King A (2020) Possible Biological Explanations for Kids' Escape from COVID-19. The Scientist.

65. Disinfecting your home if someone is sick (2020) National Center for Immunization and Respiratory Diseases (NCIRD), Division of Viral Diseases.

66. Rose C (2020) Am I Part of the Cure or Am I Part of the Disease? Keeping Coronavirus Out When a Doctor Comes Home. N Engl J Med pp: 1-3. 